\title{
Diabetes mortality and environmental heavy metals in North Carolina counties: An ecological study
}

\author{
John G. Spangler
}

Department of Family and Community Medicine, Wake Forest School of Medicine, Winston-Salem, USA; jspangle@wakehealth.edu

Received 27 July 2012; revised 26 August 2012; accepted 5 September 2012

\begin{abstract}
Introduction: Arsenic, beryllium, cadmium and nickel have been associated with the prevalence of diabetes mellitus in populations exposed to these elements. However, diabetes mortality has not been evaluated. This ecological study correlated airborne concentrations of these metals with diabetes mortality in North Carolina counties. Methods: County level data were extracted from the 2000 US Census, the 1999 US Environmental Protection Agency National Air Toxins Assessment, and 2001-2005 diabetes mortality rates by county from the North Carolina State Center for Health Statistics. Multivariable linear regression correlated airborne concentrations of each element with diabetes mellitus mortality rates in all $\mathbf{1 0 0}$ North Carolina counties controlling for county-level characteristics. Airborne concentrations were logarithmically transformed to normalize their distribution. Results: The lowest air concentrations detected were beryllium and cadmium, with nickel showing the highest concentration. Logarithmic concentrations spanned from 3.74 to 4.02 orders of magnitude. County-level diabetes mortality rates were negatively associated with median county income, but positively associated with countylevel air concentrations of arsenic, beryllium, cadmium and nickel. Conclusions: These results support diabetes mortality effects of air pollution, and agree with other studies correlating arsenic, beryllium, cadmium and nickel with diabetes prevalence. Policy implications include regulating point source air pollution.
\end{abstract}

Keywords: Diabetes Mellitus; Heavy Metals; Air Pollution; North Carolina

\section{INTRODUCTION}

Over the past decade, accumulating research points to the association between environmental heavy exposure and a number of chronic diseases, including depression, hypertension and cardiovascular disease [1]. These metals have no biological or nutritional value. However, one common theme is the association between heavy metal exposure and the development of diabetes mellitus [2-16], an effect that might involve direct cytotoxicity or autoimmunity [17]. The effects on diabetes might also impact renal disease by these metals, particularly cadmium [12]. Additionally, diabetes mellitus is a disease associated with demographic factors such as socioeconomic status and race [18].

With the incidence of diabetes mellitus increasing in the US population [19], research on this topic is necessary to elucidate the consequences of heavy metal exposure at the population level to the prevalence and mortality of diabetes [6-9]. The purpose of this study was to evaluate the relationship of environmental heavy metal exposure on diabetes mortality rates controlling for demographics at the county level in North Carolina, a state with a high prevalence of diabetes [18].

\section{METHODS}

County-level population data for North Carolina's 100 counties (total county population, total county urban population, median age and income of counties, poverty rate, and percent of the population with a high school education and race) were obtained from the 2000 US Census (population in $2000=8,049,313$ ) [20]. Diabetes age adjusted death rates for all 100 North Carolina counties (combined by the state over a four year period, 2001-2005, to ensure stability) were obtained from the North Carolina State Center for Health Statistics (NCSCHS) [21], reported as deaths per 100,000 population. Median air concentrations for arsenic, beryllium, cadmium and nickel $\left(\mathrm{mcg} / \mathrm{m}^{3}\right)$, were gathered from the 1999 national air toxic assessment by the US Environmental Protection Agency (EPA) 1999 National Scale Air Toxics Assessment [22]. The use of 1999 data ensured that any potential exposure preceded the mortality outcome. With a population over 8 million people, a 
wide array of industries and coal power plants contribute to environmental air contaminates.

Because air contaminant levels were not normally distributed, these concentrations were logarithmically transformed (to the base 10) to provide a normal distribution. Standard multiple regression was performed with diabetes mellitus mortality as the dependent variable, and heavy metal air concentrations and county factors as independent variables; thus all models controlled for population characteristics. Significance was set at p < 0.05. All data were entered into SPSS version 16 .

\section{RESULTS}

Characteristics of North Carolina counties $(n=100)$ have been described previously [23]. In brief, median county population was approximately 49,000 of which 31,500 resided in urban areas. Annual median household income was $\$ 21,578$. Seventy eight percent of residents were high school graduates, and 9 percent of the population lived at or below the poverty level.

Air contaminant levels were logarithmically transformed to ensure normal distribution and are listed in Table 1. The lowest concentrations detected were beryllium and cadmium, with nickel showing the highest concentrations. The range for concentrations of these elements spanned from 3.74 orders of magnitude to 4.02 orders of magnitude.

Results of multiple regression analysis including county and contaminate variables are listed in Table 2. These show that the diabetes mortality rates in North Carolina are negatively associated with median county income, but positively associated with air concentrations of arsenic, beryllium, cadmium and nickel.

\section{DISCUSSION}

This study has found an association between heavy metal air contaminants as measured by the EPA [22] and age adjusted diabetes mellitus mortality rates at the county level in the 100 counties of North Carolina. Although associations between these heavy metals and

Table 1. Airborne contaminant levels (logarithmically transformed to the base 10 to normalize data) of arsenic, cadmium, beryllium and nickel from the EPA 1999 National Scale Air Toxics Assessment.

\begin{tabular}{cccc}
\hline Contaminant & Minimum & Maximum & Range \\
\hline $\log [\mathrm{As}]$ & -6.92 & -2.89 & 4.02 \\
$\log [\mathrm{Cd}]$ & -7.12 & -3.33 & 3.79 \\
$\log [\mathrm{Be}]$ & -7.36 & -3.62 & 3.74 \\
$\log [\mathrm{Ni}]$ & -5.79 & -2.08 & 3.71 \\
\hline
\end{tabular}

Table 2. Multivariate regression analysis for correlates of county level diabetes mellitus death rates from the US census (2000) and the EPA 1999 National Scale Air Toxics Assessment.

\begin{tabular}{cccc}
\hline County level variables & B & Standard error & p value \\
\hline $\begin{array}{c}\text { Median income } \\
\text { (in \$1000) }\end{array}$ & -0.146 & 0.025 & $<0.001$ \\
Log [As] & 0.490 & 0.173 & $<0.007$ \\
Log [Be] & 0.648 & 0.164 & $<0.001$ \\
Log [Cd] & 0.435 & 0.200 & $<0.03$ \\
Log [Ni] & 0.553 & 0.208 & $<0.01$ \\
\hline
\end{tabular}

diabetes prevalence have been documented previously, the current study allows for estimating the effects of each contaminant on diabetes mortality among North Carolinians. For example, for each log increase in the airborne concentration of arsenic, there is a 0.49 per 100,000 population increase in diabetes mortality in North Carolina counties. Similarly, for each log increase in air concentrations of $\mathrm{Be}, \mathrm{Cd}$ and nickel there was a corresponding increase of $0.65,0.44$ and 0.56 per 100,000 population in diabetes death rates respectively. Given that the ranges of the logarithmic concentrations of As, Be, Cd and Ni were about 3 to 4 orders of magnitude (Table 1), this implies that the counties with the highest concentrations of these heavy metals in the air experienced up to a 3 to 4 orders of magnitude increase in diabetes mortality. At 3 orders of magnitude increase, this translates into 1.47, 1.95, 1.32 and 1.68 more deaths per 100,000 population attributable to the effects of arsenic, beryllium, cadmium and nickel comparing counties with the lowest versus the highest concentrations of these metals.

Studies have shown associations between these environmental contaminates and diabetes mellitus. Afridi and colleagues [2] demonstrated that arsenic and cadmium levels were higher in diabetic subjects than age-matched non-diabetic controls in hair, blood and urine. Similarly, Hemden et al. [3] demonstrated in vitro and in vivo adverse effects on pancreatic islet cells from arsenic and cadmium. Cohort studies in Taiwan [6] and Bangladesh [7] also have documented higher rates of diabetes mellitus in populations exposed to high levels of arsenic in drinking water. Despite a systematic review [9] finding inadequate evidence to support arsenic as playing a causal role in diabetes, a number of other studies have supported this hypothesis [2,3,6-9] Indeed, one group of researchers recommended more longitudinal studies to evaluate this probable relationship [9].

The evidence linking beryllium to diabetes is likely via this element's ability to induce an autoimmune T-cell response, ultimately attacking islet cells and other organs 
$[4,14,15]$. Indeed, beryllium up-regulates programmed death-1 expression on beryllium-Specific CD $4^{+} \mathrm{T}$ Cells, [16] a pathway leading to the onset of diabetes [17].

As mentioned above with arsenic, cadmium as well has been linked to diabetes mellitus [2,3]. Using NHANES III data, Schwartz and colleagues demonstrated a relationship between high urinary levels of cadmium with impaired glucose tolerance (odds ratio-1.48) [11]. Edwards and Prozialeck [12] reviewed the evidence supporting the link between cadmium exposure and diabetes, finding that cadmium reduces insulin levels, is directly cytotoxic on the pancreas and may be a factor in development of this disease. Potentially connecting cadmium to diabetes mortality, one study postulated that cadmium is likely toxic to nerve terminals, and thus may exacerbate complications from this disease [13].

Finally studies of nickel's effect on diabetes mellitus have been somewhat inconsistent. Nickel is known to avert the development of streptozotocin-induced diabetes in rats, preventing hyperglycemia [24]. Additionally, two other studies [25,26] found no relationship between nickel blood levels and diabetes in humans. By contrast, in concert with nitric oxide, nickel can induce hyperglycemia in rats [5].

It is important to note that these results are subject to a number of limitations. First, although this study controlled for many county-level risk factors for diabetes, it could not control for other confounders. Such factors might include county level obesity and heart disease rates. Additionally this analysis was unable to control for other environmental toxins known to be associated with diabetes (e.g., chromium), nor is it known the sources from which these toxins are released. In addition, since ecological studies compare data at the population level, these results cannot be extrapolated down to the individual level. For example, it could be that no person with diabetes who died in a specific county was ever exposed to these elevated environmental toxins. Finally, North Carolina does not categorize Type I versus Type II diabetes in the assessment of diabetes mortality, which slightly limits the ability to generalize to both types. Nonetheless, Type II diabetes accounts for up to $95 \%$ of all diabetes in North Carolina.

In summary, we found relationships between airborne concentrations of the heavy metals arsenic, beryllium, cadmium and nickel and county level mortality from diabetes in North Carolina. These results indicate that between 1.3 to nearly 2 deaths from diabetes per 100,000 population are attributable to these environmental contaminants. Given that the age adjusted diabetes death rate for all of North Carolina during this time period (20012005) was 27.6 per 100,000 population [27], these results imply a $5 \%$ to $7 \%$ contribution by these toxins to the state's burden of diabetes mortality. Put another way, an additional 105 to 160 North Carolinians die from diabetes mellitus as a result of these contaminants. Since coal-fired power plants contribute to $40 \%$ of total point source hazardous air pollutants [28,29]_-including arsenic, beryllium, cadmium and nickel—an analysis of these elements' concentrations based on number of coal plants per county might be a place to start to mitigate diabetes death from these pollutants. These results might also inform public policy regarding coal-fired power plant emissions.

\section{REFERENCES}

[1] Zierold, K.M., Knobeloch, L. and Anderson, H. (2004) Prevalence of chronic diseases in adults exposed to arsenic-contaminated drinking water. American Journal of Public Health, 94, 1936-1937. doi:10.2105/AJPH.94.11.1936

[2] Afridi, H.I., Kazi, T.G., Kazi, N., Jamali, M., Arain, M.B., Jalbani, N., Baig, J.A. and Sarfraz, R.A. (2008) Evaluation of toxic metals in biological samples of diabetes mellitus patients. Diabetes Research and Clinical Practice, 80, 280-288. doi:10.1016/j.diabres.2007.12.021

[3] Hemdan, N.Y., Emmrich, F., Faber, S., Lehmann, J. and Sack, U. (2007) Alterations in TH1/TH2 reactivity by heavy metals: Possible consequences include induction of autoimmune diseases. Annals of the New York Academy of Sciences, 1109, 129-137. doi:10.1196/annals.1398.015

[4] Chen, Y.W., Yang, C.Y., Huang, C.F., Hung, D.Z., Leung, Y.M. and Liu, S.H. (2009) Heavy metals, islet function and diabetes development. Islets, 1, 169-176. doi:10.4161/isl.1.3.9262

[5] Gupta, S., Ahmad, N., Husain, M.M. and Srivastava, R.C. (2000) Involvement of nitric oxide in nickel-induced hyperglycemia in rats. Nitric Oxide, 4, 129-138. doi:10.1006/niox.2000.0278

[6] Tseng, C.H., Tai, T.Y., Chong, C.K., et al. (2000) Long term arsenic exposure and incidence of non-insulin dependent diabetes mellitus: A cohort study in arseniasishyperendemic villages in Taiwan. Environ Health Perspect, 108, 847-851. doi:10.1289/ehp.00108847

[7] Rahman, M., Tondel, M. and Ahmad, KA. (1998) Diabetes mellitus associated with arsenic exposure in Bangladesh. American Journal of Epidemiology, 148, 198-203. doi:10.1093/oxfordjournals.aje.a009624

[8] Kile, M.L. and Christiani, D.C. (2008) Environmental arsenic exposure and diabetes. Journal of the American Medical Association, 300, 845-846.

doi:10.1001/jama.300.7.845

[9] Navas-Ancien, A., Silbergeld, E.K., Pastor-Barriuso, R. and Guallar, E. (2008) Arsenic exposure and prevalence of type 2 diabetes in US adults. Journal of the American Medical Association, 300, 814-822. doi:10.1001/jama.300.7.814

[10] Lai, M.S., Hsueh, Y.M. and Chen, C.J., et al. (1994) Ingested inorganic arsenic and prevalence of diabetes mellitus. American Journal of Epidemiology, 139, 484- 
492.

[11] Schwartz, G.G., Il'yasova, D. and Ivanova, A. (2003) Urinary cadmium, impaired fasting glucose and diabetes in NHANES III. Diabetes Care, 26, 468-470. doi:10.2337/diacare.26.2.468

[12] Edwards, J.R. and Prozialeck, W.C. (2009) Cadmium, diabetes and chronic kidney disease. Toxicology and Applied Pharmacology, 238, 289-293. doi:10.1016/j.taap.2009.03.007

[13] Fahim, M.A., Hasan, M.Y. and Alshuaib, W.B. (2000) Cadmium modulates diabetes-induced alterations in murine neuromuscular junction. Endocrine Research, 26, 205217. doi:10.3109/07435800009066162

[14] Fontenot, A.P. and Kotzin, B.L. (2000) Chronic beryllium disease: Immune-mediated destruction with implications for organ-specific autoimmunity. Tissue Antigens, 62, 449458. doi:10.1046/j.1399-0039.2003.00160.x

[15] Amicosante, M. and Fontenot, A.P. (2006) T cell recognition in chronic beryllium disease. Clinical Immunology, 121, 134-143. doi:10.1016/j.clim.2006.03.012

[16] Palmer, B.E., Mack, D.G. and Martin, A.K., et al. (2008) Up-regulation of programmed death-1 expression on beryllium-specific $\mathrm{CD} 4^{+}$cells in chronic beryllium disease. The Journal of Immunology, 180, 2704-2712. http://www.jimmunol.org/content/180/4/2704

[17] Ansari, M.J., Salama, A.D., Chitnis, R.N., et al. (2003) The programmed death-1 (PD-1) pathway regulates autoimmune diabetes in non-obese diabetic (NOD) mice. The Journal of Experimental Medicine, 198, 63-69. doi:10.1084/jem.20022125

[18] North Carolina Division of Public Health (2011) http://www.ncdiabetes.org/library/ pdf/Diabetes\%20burd en\%20in\%20North\%20Carolina\%202010\%20Fact $\% 20 \mathrm{~S}$ heet\%20WEB.pdf

[19] Centers for Disease Control and Prevention (2011) http://apps.nccd.cdc.gov/DDTSTRS/default.aspx
[20] US Census Bureau (2011) 2000 US census. http://www.census.gov

[21] North Carolina State Center for Health Statistics (2011) http://www.schs.state.nc.us

[22] US Environmental Protection Agency (2011) http://www.epa.gov/ttn/atw/nata1999/

[23] Spangler, J.G. and Reid, J.C. (2010) Environmental manganese and cancer mortality rates by county in North Carolina: An ecological study. Biological Trace Element Research, 133, 128-135. doi:10.1007/s12011-009-8415-9

[24] Novelli, E.L., Rodrigues, N.L. and Ribas, B.O. (1988) Effect of nickel chloride on streptozotocin-induced diabetes in rats. Canadian Journal of Physiology and Pharmacology, 65, 663-665. doi:10.1139/y88-104

[25] Kazi, T.G., Afridi, H.I., Kazi, N., et al. (2008) Copper, chromium, manganese, iron, nickel and zinc levels in biological samples of diabetes mellitus patients. Biological Trace Element Research, 122, 1-18. doi:10.1007/s12011-007-8062-y

[26] Yarat, A., Nokav, S., Ipbuker, A. and Emekli, N. (1992) Serum nickel levels of diabetic patients and healthy controls by AAS with graphite furnace. Biological Trace Element Research, 35, 273-280. doi:10.1007/BF02783771

[27] North Carolina State Center for Health Statisitics (2011) http://www.schs.state.nc.us/SCHS/deaths/lcd/2005/diabet es.html

[28] Environmental Health and Engineering (2011) Emissions of hazardous air pollutants from coal-fired power plantsA study commissioned by the American Lung Association. Environmental Health and Engineering, Needham. http://www.lungusa.org/assets/documents/healthy-air/coalfired-plant-hazards.pdf

[29] (2012) North Carolina Diabetes Prevention and Control Branch, North Carolina Department of Health and Human Resources, Raleigh. http://www.ncdiabetes.org 